\title{
Centros Ocupacionais de Reintegração Social
}

\author{
(Prisões abertas)
}

\author{
Mário Cesar de Moraes Pitão
}

\begin{abstract}
"Il n'y a aucune chose qui satisfasse le pénaliste davantage que la certitude qu'il est arrivé à reclasser ses hommes par des moyens toujour plus libéraux."
\end{abstract}

Kellerhals

$\mathrm{D}_{\mathrm{s}}$

ENTRE os sistemas penitenciários conhecidos - o de Filadélfia, o de Auburn e o Progressivo - é, indubitàvelmente, êste último, o que maiores influências tem exercido em nosso país, e também, o que melhor atende às necessidades da vida moderna.

Formulado por JoshuA JEBB e aplicado nas prisões da Irlanda por WALTER CROFTON (1) com algumas modificações, o sistema progressivo também é conhecido como irlandês, consistindo de várias fases cujos pontos extremos são o isolamento celular e o livramento condicional.

No Brasil, o sistema progressivo foi adotado pelo Código de 1940, em seu artigo $30, \S \S 1 .^{\circ}$ e $2 .^{\circ}$, quando estabeleceu a fase do trabalho em comum com os demais detentos, dentro ou fora do estabelecimento correcional, além de permitir a transferência do sentenciado para colônias penais, desde que tenha revelado bom comportamento.

Se tomarmos o exemplo paulista, verificaremos que, na Penitenciária de São Paulo, o condenado passa por tôdas as fases dêste sistema. (2) Há, inicialmente, um isolamento celular, não tão rígido como o criado pela Walnut Street Jail (Filadélfia), enı 1817, logo seguido da fase do trabalho em comum, aprendizado técnico, para atingir a penúltima fase, qual seja o trabalho agrícola, ocasião em que o sentenciado é enviado para a Colônia Agrícola de Taubaté ou, então, passa a trabalhar ao ar livre, nos próprios terrenos de cultura da Penitenciária. (3) A última fase é representada pela liberdade condicional, atendidos os requisitos do artigo 60 do Código Penal.

Aliás, em recente visita realizada a São Paulo, (*) tivemos a oportunidade de ver que lá o sistema progressivo é mais ou menos executado, pois,

(*) Caravana de Estudos Penitenciários, integrada por membros da AuREx, acompanhados do ilustre catedrático de Direito Penal da Faculdade Nacional de Direito, prof. Demósthenes Madureira de Pinho (29 de junho -2 de julho de 1955). 
conforme salienta Pedro Vergara, entre a esquematização teórica do Dr. ACÁCIo Nogueira e a prática, existe uma sensível diferença.

O XII Congresso Penal e Penitenciário de Haya (1950), ao apreciar a tese apresentada por CHARLeS Germain, diretor da Administração Penitenciária da França, (4) vem de criar uma nova etapa ao método gradativo, porquanto, as prisões abertas - estabelecimentos penais onde a self-responsability é a estrutura do sistema, visto como não são os obstáculos materiais (muros, grades, ferrolhos, etc.) que infundem ao condenado a consciência de estar cumprindo pena - não poderão, a nosso ver, ser utilizadas sem que o condenado haja, antes, percorrido um longo caminho de observação, iniciado em prisões de segurança máxima e média para, finalmente, atingir a última concepção da ciência penitenciária moderna.

E êste, também, o pensamento da Direção Geral das Prisões da Venezuela, manifestado no Seminário Latino-Americano sôbre a Prevenção do Delito e Tratamento do Delinqüente (5) e, entre nós, o de VictóRio CANEPPA, em sua excelente monçgrafia sôbre o problema em foco, (6) que não admite outra hipótese sem o risco de desmoronamento total do novo regime.

Em palestra mantida com êsse profundo conhecedor da ciência penitenciária, representante no Brasil do Grupo Permanente de Trabalho LatinoAmericano de Defesa Social (O.N.U.), disse-nos êle que criar prisões abertas no Brasil é muito problemático, visto como nosso país está desprovido e desaparelhado para a grande tarefa de indicação dos elementos aptos para serem enviados às novas prisões, certamente porque, na prática, os institutos, encarregados de tal observação, não nos chegam a dar o mínimo necessário para a consecução do objetivo colimadc. Flamínio FÁvero, igualmente, é apologista do método gradativo, quando afirma que "os que não estiverem em condições de receber êsse tratamento (prisões abertas), serão submetidos ? outro, nos presídios semi-abertos ou fechados, até poderem chegar àque $a$ etapa". (7).

Pelo exposto, verificamos que é sumamente necessária uma seleção dos detentos a serem enviados às prisões abertas. Convém salientar que esta seleção não deverá ficar adstrita, ùnicamente, aos detentos, mas, ao contrário, a todo o pessoal encarregado da direção do estabelecimento que deverá estar capacitado para as altas funções a serem desempenhadas. Assim, teríamos, a nosso ver, dois pontos a serem examinados: seleção de detentos e seleção de dirigentes.

Seleção dos detentos - No que tange à seleção dos condenados, o problema se nos afigura muito delicado, porquanto, embora alguns indivíduos se achem, desde logo, aptos ao ingresso no estabelecimento aberto, outros nunca conseguirão ultrapassar as prisões de segurança máxima. Por isto, com bastante razão, formulou o Congresso de Haya numa de suas resoluções: "Les prisonniers renvoyés dans un établissement ouvert devraient être choisis attentivement..." (número 3 , letra $\mathrm{f}$ ).

Em vista disso, sugeríamos que o sentenciado fôsse, prèviamente, submetido a rigorosos estudos, não só biológicos e antropológicos como também de ordem psicológica. Êstes, sobretudo, mereceriam a maior atenção: a persona- 
lidade do delinqüente seria alvo de profundo e apurado estudo, através da aplicação de testes e exames, possibilitando que as principais nuanças de sua vida interior fôssem conhecidas do pessoal especializado a quem caberia indicar aquêles que estariam aptos para serem transferidos à etapa final do método gradativo.

$\mathrm{Na}$ apreciação da personalidade do recluso, a meta a ser percorrida, salvo melhor exame, deveria partir da "classificação experimental" de José MARIA Alkimin, grande conhecedor da matéria e antigo diretor da Penitenciária Agrícola de Neves, que propõe duas etapas:

“a) uma primeira separação dos condenados que possam, logo de entrada no cárcere, oferecer garantias à confiança nêles depositada;

b) dos condenados, que, ao primeiro exame, pareçam possuir deficiência de ordem moral; não se detendo, porém, a administração a critérios estreitos". (8).

Embora Alkimin não desenvolvesse êste importante estudo totalmente, ficando sem referência a classsificação dentro do segundo grupo, chegar-se-ia às idéias de LEMOS BRITo que se baseiam, essencialmente, no estudo do delinqüente, apreciando devidamente, com todo o critério e boa vontade, sua periculosidade e inadaptação. (9).

É preciso que se tenha em mente, porém, que qualquer classificação, que se pretenda efetuar, não poderá apresentar $a b$ initio, resultados satisfatórios. O delinqüente não poderá, ex-abrupto, fornecer dados suficientes que permitam incluí-lo neste ou naquele grupo. Sòmente o estudo e a cuidadosa observação solverão essa dificuldade, pois o tempo se encarregará de trazer à superfície tôdas as simulações, aclarando os elementos que, até então, se mostravam anuviados, desafiando a experiência dos peritos.

A Direção Geral das Prisões da Venezuela, ao estudar os Estabelecimentos Penais e Correcionais Abertos, declara que a Seção de Observação Criminológica (entre nós poderia chamar-se Departamento de Informação Criminológica - D.I.C.) deverá, entre outras medidas, confeccionar uma ficha e um expediente de cada recluso, nêles sendo anotadas tôdas as observações concernentes à sua personalidade. Poderíamos acrescentar, seguindo a sugestão de CANEPPA, que fôsse assentado, nesssas fichas, todo o progresso educacional, social e profissional do delinquiente. Outrossim, não deveriam ser descuradas as questões referentes à mesologia, endocrinologia e, principalmente, à orientação profissional.

Esta última apresenta grande relevância. À primeira vista, acredita-se que uma prisão aberta seja uma colônia agrícola, isto porque, no Brasil, Neves, que mais se assemelha a uma prisão aberta, apresentando-se com o regime ALL APERTO das famosas colônias penais italianas da Ilha da Sardenha (regime de ampla liberdade nas fazendas de Lage, Mato Grosso e Retiro), é uma colônia agrícola.

Entretanto, conforme acentua BASILEU GARCIA, (10) em tôdas as grandes penitenciárias agrícolas do mundo há seçõęs industriais e Neves também as possui. Numa prisão aberta é certo que o trabalho agrícola proporcionará maiores benefícios, pois o indivíduo é colocado, diretamente, em contato com a natureza, ao sol ou à chuva, na mais completa liberdade. 
Além disso, deve-se atender, também, aos fatôres econômicos. O Brasil é uma nação essencialmente agrícola. São Paulo, onde a maior indústria do país está localizada, continua a ser predominantemente agrícola, e a origem rural dos presos já foi lá constatada por ALFREDo ISSA ÁSSALY, quando subdiretor da Penitenciária daquele Estado. (11)

Não obstante, a fim de evitar a desambientação profissional dos presos, é necessária a existência de seções industriais na própria prisão aberta. Seriam elas destinadas àqueles que não possuíssem tendência alguma para a lavoura, procedentes, muitas vêzes, de grandes centros urbanos. HuÁscar CAJIAS K., ao estudar o assunto em relação a Bolívia, diz textualmente: "En efecto, considerando que lo que se busca es la readaptación del criminal y como a éste no se le puede cambiar radicalmente el sistema de vida y trabajo futuros con respecto a los que tenía antes de delinquir, será necesssário pensar en que el trabajo realizado en el establecimiento tendrá características urbanas y campesinas". (12)

Na prisão aberta, porém, deveria ser levado, em grande conta, o disposto no artigo 31 , parágrafo único, do Código Penal: "O trabalho, desde que tenha caráter educativo, pode ser escolhido pelo detento, na conformidade de suas aptidões ou de suas ocupações anteriores". O dispositivo legal deveria, contudo, ser interpretado de forma ampla, como verdadeiro direito do detento, isto porque, acreditamos, o reduzido número de habitantes de uma colônia, aberta lhes permitiria o direito de opção. Uma prisão aberta não deveria possuir, a não ser que a experiência demonstrasse o contrário, mais de 200 internos, pois o grande número prejudicaria, sobremaneira, o fim colimado recuperação moral do detento - ou a própria estrutura do sistema.

Seleção dos Dirigentes - - Além dos pontos examinados, que tocam ùnicamente ao detento, há outros, também de capital importância, que se referem à seleção do pessoal dirigente. Uma nova concepção na ciência penitenciária, tão arrojada como as prisões abertas, necessitaria, para ser conveniente e satisfatòriamente executada e, mesmo, para a própria viabilidade do sistema, de um corpo selecionado de diretores (funcionárics). (*) Dêle dependeria, em grande parcela, a boa execução do regime, servindo êles de orientadores e conselheiros, assistindo, de maneira tôda especial, com brandura, abnegação e até mesmo carinho, aos detentos, tentando infundir-lhes, cada vez mais, as noções de auto-responsabilidade, além de explorar-lhes os bons dotes da personalidade.

A função recuperadora dos criminosos se tornará bastante difícil se não se tiver, ao alcance, indivíduos capacitados para desempenhar tão elevada missão. A auto-responsabil:dade, infundida aos detentos, deverá, da mesma forma, estar sempre presente nos dirigentes. Torna-se, pois, indispensável que tenham êles consciência do alto papel que representam, porque, do contrário, desmoronará todo o trabalho, longamente preparado.

Insinuaríamos a criação de cursos, destinados à formação de técnicos, devendo-se aproveitar a colaboração de asssistentes sociais, médicos, advoga-

(*) A Prisão Aberta de Santa Fé, em Maceió, com 80 delinqüentes, possui, apenas, 10 funcionários. A Vila São João (Penitenciária Agrícola de Itamaracá) em Pernambuco, com 143 pessoas (detentos e famílias) só possui, também, 10 funcionários. Cf. CANeppa. 
dos, etc. Poder-se-ia, ainda, estabelecer contato com o O.N.U., visando a obtenção de bolsas de estudo para os que se interessassem pelo assunto os quais observariam, in loco, o problema Michigan Corrections e Penitenciária E1 Chino, nos Estados Unidos; Prisöes da Ilha da Sardenha, na Itália; Prisões Borstal na Inglaterra), anotando as possibilidades de implantação de métodos semelhantes para a questão brasileira e, mesmo, formando novos técnicos e especialistas brasileiros.

Não deveria ser despresada, igualmente, a realização de seminários, onde o problema poderia ser amplamente ventilado e debatido frente à realidade brasileira.

PORQUE SOMOS APOLOGISTAS DOS CENTROS OCUPACIONAIS DE REINTEGRAÇÃO SOCIAL (CORES)

O Brasil já possui algumas prisões abertas em funcionamento, embora nãn totalmente concluídas: Santa Fé, em Maceió; Canavieiras, em Santa Catarina; Neves, em Minas, e Penitenciária Agrícola de Itamaracá, em Pernambuco. Fala-se, também, em um projeto, criando uma prisão aberta em Jundiaí, a qual viria servir de etapa posterior à Colônia de Taubaté, de São Paulo.

A nosso ver, as prisões abertas, pelas suas características intrínsecas, não podem ser mais consideradas estabelecimentcs penais e sim Centros Ocupacionais de Reintegração Social (CORES), denominação esta que proporíamos fôsse adotada doravante. A denominação prisões abertas é, em si, um paradoxo! Os individuos que para lá são enviados já não são mais criminosos, porém, desajustados sociais a quem o Estado proporcionará tratamento adequado.

- Embora, em nosso país, as prisões abertas se encontrem, ainda, em fase incipiente, acreditamos que essa será a tendência futura. Atualmente, constatamos que elas nada mais são que fazendas. Confiamos, pois, que, posteriormente, os CORES se transformem em verdadeiros bairros em miniatura, possuindo escola, cinema, cantina, praças de esporte, capela, etc., sendo tôda a readaptação feita através de sã disciplina, verdadeiro espírito de justiça, brandura e tolerância.

Os CORES não deverão estar situados a grande distância dos centros urbanos, a fim de que os desajustados possam viver, com suas famílias, em pequeninas casas, garantindo-se, à semelhança do projeto venezuelano, a inviolabilidade de domicílio, e sòmente se permitindo a entrada, nos lares, aos funcionários expressamente autorizados pelo Diretor do Centro.

A convivência em família é uma das pedras angulares dos CORES. O sentenciado, ao ser enviado para a Penitenciária, ocasiona um desequilíbrio total na vida de seus dependentes porque, sendo o esteio da família, não mais poderá prestar-lhe o cuidado necessário. Deixa, assim, de funcionar a pedra principal do maquinismo, provocando iminente colapso.

Tentando solucionar êsse grave problema, permitiu o govêrno, em Neves, a construção de casas fora da prisão e, na Ilha Grande, que as famílias vivesserı próximas aos sentenciados. Entretanto, a medida foi mal planejada, não se levando em conta as distâncias. Neves ainda produziu alguns resultados e, 
em certa ocasião, havia cêrca de 50 famílias lá residindo, segundo nos relata Negley K. Teeters. Todavia, o autor de Penology from Panama to Cape Horn, diz, logo adiante, textualmente: "When $I$ visited the institution $I$ was told by the director that only two such families were there and that the practice was slowly being abandoned. Enthusiasm for this type of penalcommunal living has apparently died down in Minas Gerais" (pg. 241).

(*) Quanto à Colônia da Ilha Grande, perdeu, desde logo, suas finalidades e, atualmente, abriga os presos da pior espécie.

Tendo em vista êsses aspectos e, lembrando-nos de que o sentenciado, segregado do lar, longe dos seus entes queridos, dos seus filhos que, com o tempo, não the demonstrarão a menor parcela de afeto ou carinho, terá, imperativamente, de desenvolver um sentimento de repulsa para com a sociedade, causa eficiente da sua irrecuperabilidade.

Dêste modo, torna-se imediatamente necessário que resida com sua família, o que será perfeitamente possível nos CORES, não mais portadores dos êrros dos sistemas precedentes: localizar-se-ão, os CORES, próximo aos centros urbanos, em lugares de fácil acesso, embora não se situem dentro do perímetra urbano.

A vida em família solucionará a tão debatida questão sexual nas prisões. De fato, conforme salienta FlORA VELOso, as prisões abertas são "um símbolo de sexualidade, no sentido analista, de proporcionar aos condenados uma vida sexual normalizada, a fim de que os mesmos sejam recuperados". (13) Evitar-se-á, desta maneira, a degradante câmara reservada, que tantas polêmicas têm suscitado.

Outro fator que demonstra a vantagem da criação dos CORES é que o condenado deixaria de estar segregado do meio social. Seus dirigentes procurariam, a cada momento, proporcionar-lhes atividades em que houvesse um contatc direto entre a cidade e o CENTRO. Captar-se-ia o interêsse do grupo social para a realização de exposições de pintura, trabalhos manuais, etc.:, que teriam lugar nas dependências do próprio CENTRO. Por outro lado, os desajustados que tivessem demonstrado aptidão, teriam seus trabalhos iniciados às demais exposições, havendo um estreito intercâmbio.

Também poderiam ser realizados concursos, outorgando-se, mesmo, prêmios em dinheiro, visando a desenvolver o nível intelectual dos sentenciados; igualmente, incrementadas as competições desportivas, através de jogos de futebol, basquete, voleibol etc., desenvolvendo-se uma sã camaradagem que agiria, benèficamente, sôbre a mente dos desajustados.

A imprensa e o rádio seriam chamados à divulgação dos acontecimentos mais importantes que lá se realizassem, perdendo, assim, a característica atual de denunciar, em grandes epígrafes, sòmente os fatos que prejudicam e diminuem o conceito do delinqüente.

Os relatos de crimes e suicídios de maneira a provocar sensação, característica do baixo jornalismo Yellow press, deveriam ser expressamente proí-

(*) Atualmente, Neves, sob a eficiente direção do Dr. Alberto Teixeira dos Santos Filho, com quem estivemos recentemente, abriga 65 famílias. 
bidos por lei, pois são êles um convite permanente à delinqüência. Se o indivíduo errou, nosssa misssão é apontar-lhe o êrro e recuperá-lo e não mostrar a todos sua falta, em grandès manchetes, como se isso fôsse um divertimento. O problema é muito mais sério e deve merecer de todos, principalmente de nossas autoridades, a melhor compreensão e boa vontade.

Fomos, na Faculdade Nacional de Direito, um dos fundadores da Associação Universitária de Recuperação de Ex-Detentos (AUREX), entidade que tem recebido o apoio e o aplauso das autoridades e do público em geral. Nos três meses, apenas, de sua existência, a AUREX já tem prestado inumerável assistência aos egressos das Penitenciárias da Capital Federal, atendendo aos preceitos de seus estatutos que assinalam, como objetivos da Associação, a recuperação do ex-detento, em todos os sentidos, e a assistência moral aos presidiários.

Agora, perguntamos: porque foi fundada a AUREX? Porque nosso sistema penitenciário tem-se mostrado evidentemente falho. Se a sociedade tem o direito de segregar o indivíduo que delinqüiu, afirmamos que também terá o dever de recebê-lo de volta, quando tiver pago sua dívida, com a pena. Entretanto, não é isso o que ocorre. O delinqüente, ao deixar as grades da prisão, acha-se como que infectado, é portador de uma terrível moléstia: $A$ Lepra Social!

Houvesse o sistema penitenciário sido melhor examinado e o choque sofrido pelo liberto seria mínimo, quase que imperceptível porque, de há muito, a sociedade já o teria recebido. Os Centros Ocupacionais de Reintegração Social cumprem, perfeitamente, essa finalidade! Daí, a necessidade de sua criação e multiplicação, por todo o Brasil, atendidos os requisitos a que já nos referimos.

Não desejamos terminar estas considerações sem lançar um fervoroso apêlo aos apologistas destas cusadas idéias na ciência penitenciária - as prisões abertas ou Centros Ocupacionais de Reintegração Social - no sentido de que seja planejado e examinado, com atenção, cuidado e carinho, êsse aspecto da penalogia moderna, pois utilizados com a devida cautela, os Centros Ocupacionais de Reintegração Social representam, a nosso entender, o passo mais acertado e liberal do Direito Penitenciário de nossos dias!

\section{REFERÊNCIAS BIBLIOGRĀFICAS}

(1) Teeters, Negley K. - Penology from Panama to Cape Horn, 1946,8.

(2) Nogueira, Acácio - A Penitenciária de São Paulo; "Rev. Pen. e Penitenc.", ano I, vol. I, fasc. I, 18-25.

(3) Garcia, Basileu - Instituições de Direito Penal; vol. I, tomo I, 1954, 417.

(4) ACTES - XII Congrès Pénal et Pénitentiaire International, La Haye 14-19 Août 1950, vol. I, 136-152, 168-192.

(5) Seminário Latinoamericano sobre la Prevención del Delito y Tratamiento del Delinquente - "Estabelecimentos Penales y Correccionales Abiertos"; Dirección General de Prisiones, Venezuela; 1953.

(6) CANEPpa, Victorio - Prisöes Abertas, set. 1954.

(7) Fávero, Flamínio - Prefácio à monog de Victorio Caneppa. 
(8) Vergara, Pedro - Das Penas Principais e sua Aplicação, 1948.

(9) BRITo, Lemos - Da Imprescindibilidade da Classificação dos Sentenciados como Base de Qualquer Sistema Penitenciário - Seminário Latino-Americano sôbre a Prevenção do Delito e Tratamento do Delinqüente. Rio Jan. 6-19 abr. 1953.

(10) Garcia, Basileu - obra citada, pg. 436.

(11) Ássaly, Alfr. Issa - o Trabalho Penitenciário, 1944, 128-151.

(12) Cajías K., Huascar — Los Establecimientos Penales y Correccionales Abiertos en Relación con la Realidad Boliviana. Sem. Lat-Amer. Prev. Del. Trat. Delinq., abril 1953.

(13) Veloso, Flora - Prisões Abertas - Da Importância da Psicologia Profunda na Estrutura das Prisões Abertas - IV Reunião da Assoc. Bras. Prisões Belo Horiz. março, 1955.

\section{SUMMARY}

1. The three penitentiary systems: the system of Philadephia, the Auburn and the Progressive. The influence of the last mentioned in Brazil; its adoption since 1940.

2. The system of the Penitenciária de São Paulo, analyzed.

3. The 125h Penal and Penitentiary Congress of The Hague (1950) and the new concept of the progressive system. The open door system based on self-responsibility cannot be adopted, according to the Author, without a long period of observation, in prisons of maximum and median conditions of safety, aiming at the ultimate attainment of the said system. This is also the position of the General Direction of Venezuelan Prisons and the opinion of Victorio Caneppa.

4. The necessity of selection of elementos to be sent to the open prisons. Brazil not yet equipped with the means for such selection. The opinions of Victorio Caneppa and of Flaminio Fávero en the matter.

5. The problem of careful selection of prisoners for the open door establishments, analyzed in detail. The individual study ot the prisoners as the basis for such selection. The ideas of José Maria Alkimin and of Lemos Brito on the matter. The problem as approached by the General Direction of Venezuelan Prisons.

6. The open door prisons and the predominance of agricultural work in them The inportance of having also instituted units for industrial work in such prisons.

7. The importance of the adequate selection of directors and staff for the prisons.

8. The possibility of having instituted special training courses for the staff men-: tioned in item 7, above. The possible collaboration of the U.N. and the granting of scholarships for persons interested in studying the problem in special centres abroad. The organization of seminars in Brazil, for the discussion of the problem.

9. The Brazilian open door prisons in operation, although not in full. The open prisons, according to the Author, are true occupational centres of social reintegration. The preference to be given to such denomination: its psychological significance. The prospective ideal organization of such centres advocated by the Author; the maintenance of family life in them; the sncial activities such as exhibitions of painting, industrial arts, etc.; the organization of competitive examinations with distribution of prizes; the practice of sports; the collaboration of the Press and or the Radio, being avoided sensational news.

10. The Associação Universitária de Recuperação de Ex-Detentos (Aurex); its activities analyzed. A final plea in favour of the Occupational Centres of Social Reintegration. 